\title{
Study on Evacuation Evaluation in Subway Fire Based on Pedestrian Simulation Technology
}

\author{
Yanyan Chen, ${ }^{1}$ Yiwen Cai, ${ }^{1}$ Pingpu Li, ${ }^{2}$ and Guanghou Zhang ${ }^{3}$ \\ ${ }^{1}$ Transportation Research Center, Beijing University of Technology, Beijing 100124, China \\ ${ }^{2}$ Beijing General Municipal Engineering Design \& Research Institute, Beijing 100082, China \\ ${ }^{3}$ Institute of Comprehensive Transportation of National Development and Reform Commission, Beijing 100038, China
}

Correspondence should be addressed to Yiwen Cai; caiyiwen920105@163.com

Received 6 July 2014; Revised 7 November 2014; Accepted 10 November 2014

Academic Editor: Hong Chen

Copyright (C) 2015 Yanyan Chen et al. This is an open access article distributed under the Creative Commons Attribution License, which permits unrestricted use, distribution, and reproduction in any medium, provided the original work is properly cited.

\begin{abstract}
In order to improve the ability to evacuate from subway fire in subway's planning, design, operation, and maintenance stages, a simulation model of pedestrians' evacuation process in subway fire was established based on Legion and FDS software. It can truly reflect the dynamic effects of the fire environment on subway station evacuation. Then dynamic evaluation indicators systems were established from the point of survival index, security risk index, effectiveness index, and orderliness index. In order to help decision makers to identify the most appropriate plan, matter-element analysis (MEA) was used to rate different plans. At last a case study of Songjiazhuang (SJZ) station was provided to test the effectiveness and practicability of the evaluation method.
\end{abstract}

\section{Introduction}

The subway, as one of urban public transportation means, due to the large capacity, land saving, and so forth, is becoming an effective tool to alleviate urban traffic congestion. But subway is a place where the disasters and accidents happened easily owing to its characteristics of being complex, close, agglomerate, and so on. Of all these disasters, fire is the most serious. Therefore, it is necessary to evaluate different pedestrians' evacuation plans facing with different fire conditions in subway's planning, design, operation, and maintenance stages. Because of the particularity of fire accident, the drilling method has many shortcomings such as big-cost, time-consuming, and more participants. And in the planning and design stages, it is difficult to evaluate and optimize the fire evacuation facility and pedestrians' evacuation plan.

With the development of computer technology, simulation technology of subway fire has become a way of highfeasibility, low-cost, and good-effect. Based on the reasonable parameter calibration, the simulation model can truly reflect the status of subway fire and record the data of pedestrians' speed, acceleration, density, coordinate, and other traffic behavior. It provides a strong support for the quantitative evaluation of fire evacuation situation and has been widely used in all areas [1-5].

There have been many researches [6-8] about evaluation of fire evacuation in subway station at home and abroad. However, the evaluation systems have a lot of shortages in different degrees. Firstly, there are still some qualitative indicators in exiting evaluation system. Setting value of these indicators needs to be finished by experts. Thus, qualitative indicators are limited to the experience of the experts or decision makers and the values might be not objective and convictive. Secondly, quantitative indicators are not reasonable enough to be selected and quantified. And they cannot reflect pedestrians' behavior dynamically in the evacuation process. Thus, the evacuation situation cannot be reflected accurately. At present, qualitative description or basic comparison of simulation results is still the main application method of pedestrian simulation tools. The simulation evaluation method is not versatile because of lacking of standard dynamic evaluation indicators system and procedure.

In this paper, a model of pedestrians' evacuation process in subway fire is established based on Legion and FDS simulation software, and a dynamic evaluation indicators system 
TABLE 1: Details of parameters.

\begin{tabular}{ll}
\hline Parameters & Details \\
\hline Facility layout & $\begin{array}{l}\text { Stairs, escalators, ramps, brake } \\
\text { machine, etc. }\end{array}$ \\
\hline $\begin{array}{l}\text { Pedestrian } \\
\text { characteristics }\end{array}$ & $\begin{array}{l}\text { Age ratio, culture degree, sex ratio, } \\
\text { etc. }\end{array}$ \\
\hline Demand & $\begin{array}{l}\text { The number of pedestrians, } \\
\text { distribution }\end{array}$ \\
\hline Pedestrian behavior & $\begin{array}{l}\text { Along the wall, clustering behavior, } \\
\text { panic behavior }\end{array}$ \\
\hline Regions & $\begin{array}{l}\text { Walking region, waiting region, } \\
\text { isolation region, danger zone }\end{array}$ \\
\hline Environment calibration & $\begin{array}{l}\text { Speed reduction, path choice, life } \\
\text { characteristics }\end{array}$ \\
\hline
\end{tabular}

TABLE 2: Output parameters of Legion.

\begin{tabular}{lc}
\hline Output format & Output parameters \\
\hline & Ingress and egress \\
& Occupancy \\
& Flow \\
Map & Speed \\
Chart & Entity and space density \\
Table & Journey time \\
& Social cost \\
& Inconvenience and frustration discomfort and \\
& dissatisfaction \\
\hline
\end{tabular}

is also established. A case is used to verify its effectiveness and practicability.

\section{The Evacuation Evaluation in Subway Fire}

2.1. Pedestrian Simulation Technology: Legion and FDS. The multiagent pedestrian model is the heart of the Legion simulation tool which uses the "minimum cost" [9] as the basic principles. Field investigation and data preparation are the basic work for pedestrian simulation modeling. Therefore, the parameters in Table 1 should be calibrated in building a simulation model.

Legion can record detailed track of each individual pedestrian and can accurately calculate the individual traffic behavior parameters and macroscopic traffic flow characteristics of pedestrian. The status of pedestrian traffic system can be reflected by maps, charts, and tables. Detailed output parameters can be found in Table 2.

Fire dynamics simulator (FDS) is the computational fluid dynamics simulation software in the fire, which was developed by the US national institute of standards technology. FDS can solve continuity equation, momentum equation, energy equation, and stress convergence equation with large eddy simulation (LES) model. Then the spatial distribution of temperature, pressure, gas composition, visibility, and so forth can be got [10]. FDS was validated by a lot of engineering experiments, and it is recognized by the international fire engineering.
2.2. The Process of Simulation Evaluation. The simulation is a method to simulate the complicated traffic phenomenon by computer technology and to display the real-time traffic situation based on the forecasting. Then the work of analysis, evaluation, and optimization can be started. The process of pedestrians' evacuation evaluation in subway fire based on the simulation technology is shown in Figure 1.

\section{Pedestrian Evacuation Evaluation Indicators System in Subway Fire}

3.1. Indicators System and Quantification of Indexes. It is vital to ensure that pedestrians' evacuation in subway fire is effective and safe. The evaluation of subway fire evacuation is used to investigate the merits degree of survival index, security risk index, effectiveness index, and orderliness index under different conditions such as facility layout and evacuation plan. The dynamic pedestrians' evacuation evaluation indicators system in subway fire based on the output parameters of Legion is shown in Figure 2.

3.1.1. Survival Index. Survival index reflects the survival probability directly in the evacuation process. It can be described as two aspects: one is survival ratio and the other one is survival reliability.

(1) Survival Ratio $u_{11}$. The index reflects pedestrians' survival situation in the evacuation process:

$$
u_{11}=\frac{q}{Q} \times 100 \% .
$$

In the type, $q$ stands for the amount of evacuation pedestrians; $Q$ is the total amount of pedestrians.

(2) Survival Reliability $u_{12}$. Due to the randomness of pedestrians' evacuation process, there will exist distance between deterministic methods to describe the evacuation process and actual situation. So this paper uses survival reliability index to describe pedestrians' evacuation process.

In the process, if available safe evacuation time (ASET) is longer than required safe evacuation time (RSET), pedestrians will be safe. That is,

$$
\text { ASET }- \text { RSET }>0 .
$$

According to the above criterion, the limit state equation for pedestrians' safe evacuation can be constructed:

$$
Z=T_{A}-T_{R}>0 .
$$

$T_{A}$ stands for ASET and $T_{R}$ stands for RSET. The unit is "s." $T_{A}$ is mainly affected by the fire situation; it can be got by FDS in all regions. $T_{R}$ can be got by Legion and obeys the normal distribution according to existing research [11].

Obviously, $Z$ obeys the normal distribution, and its mean $\mu_{z}$ and standard deviation $\sigma_{z}$ are as follows:

$$
\begin{gathered}
\mu_{Z}=T_{A}-\mu_{T_{R}}, \\
\sigma_{Z}=\sigma_{T_{R}} .
\end{gathered}
$$




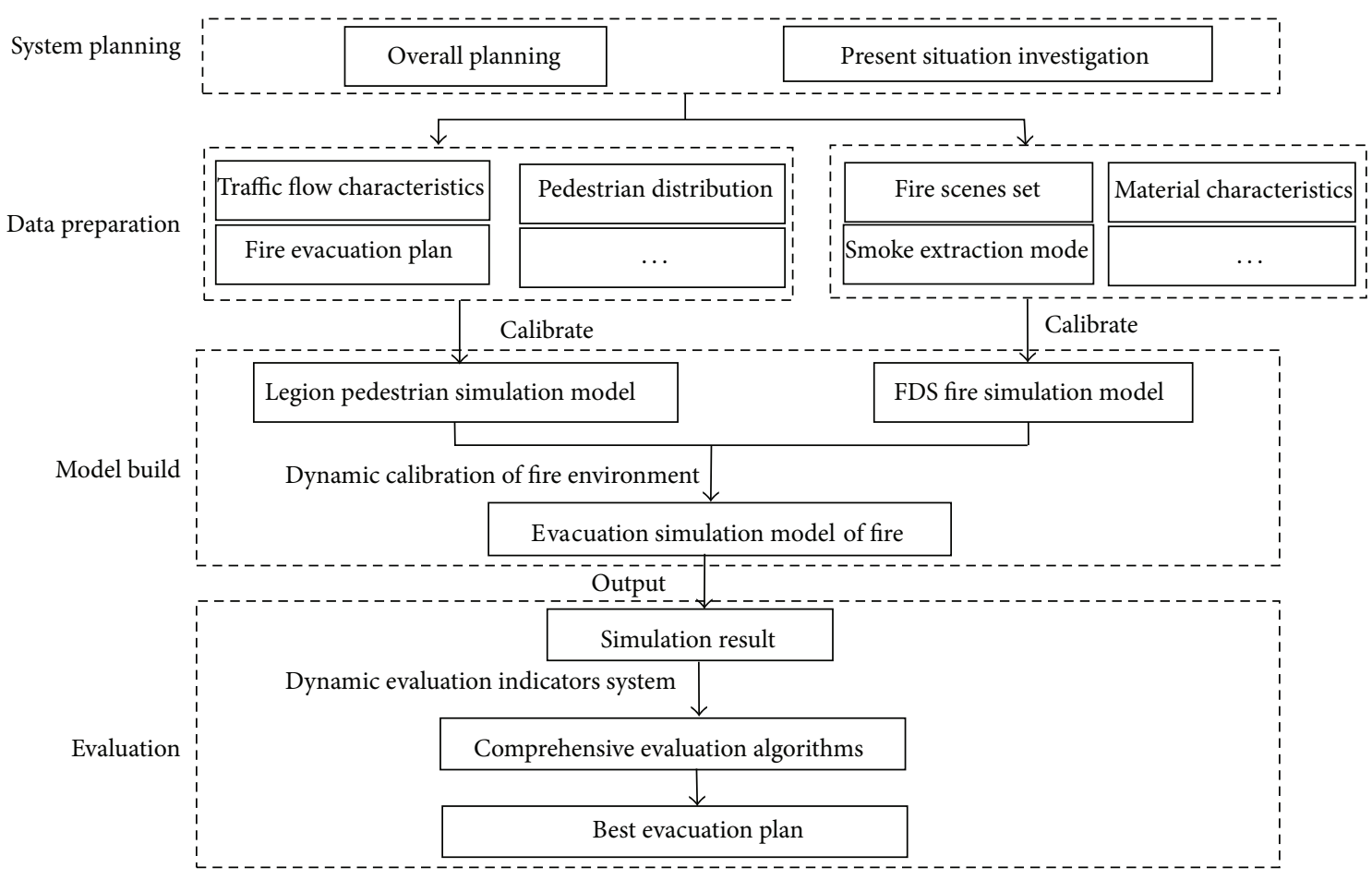

FIGURE 1: The process of pedestrians' evacuation evaluation based on the simulation technology.

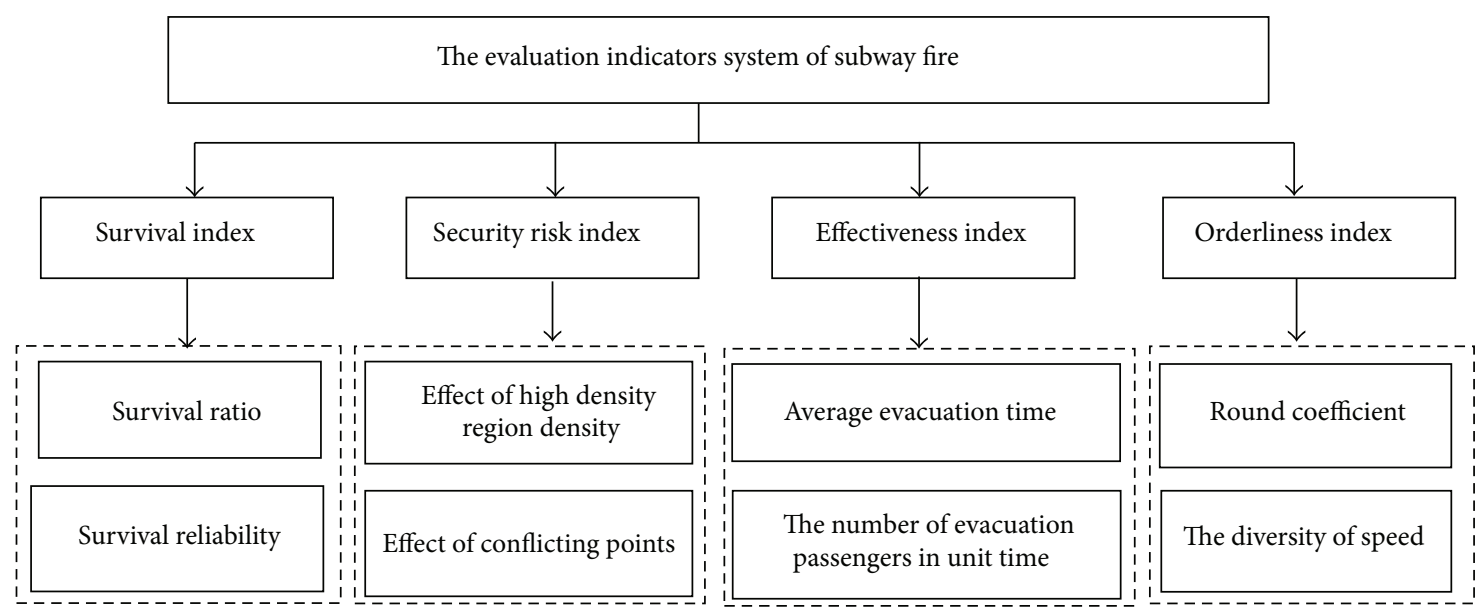

FIgure 2: Pedestrians' evacuation evaluation indicators system in subway fire.

$\mu_{T_{R}}$ and $\sigma_{T_{R}}$ are $T_{R}$ 's mean and standard deviation. The reliability index of safe evacuation $(\beta)$ can be indicated as follows:

$$
\beta=\frac{\mu_{Z}}{\sigma_{Z}}
$$

Then, $u_{12}$ can be described as follows:

$$
\mu_{12}=P(Z>0)=\phi(\beta) .
$$

In the type, $\phi(\cdot)$ is standard normal distribution function.

3.1.2. Security Risk Index. In pedestrians' evacuation process, some high density and serious conflicting regions are often high probability of accidents. There is security risk that should be avoided.

(1) Effect of High Density Region $u_{21}$. This index reflects the effect of high density. It can be considered that regions under " $D$ " service level are high density [12]. The formula takes time of duration and affected passenger flow into account:

$$
u_{21}=\frac{\sum_{i=1}^{e} \sum_{j=1}^{m_{i}} l_{i j} \cdot v_{i j}}{T_{t} \cdot q_{t}} .
$$

In the type, $e$ is the number of high density regions, $m_{i}$ is the number of high density time periods in region $i, l_{i j}$ is the length of time period $j$ in region $i$ and the unit is "s," $v_{i j}$ is 
the number of passengers during time period $j$ in region $i, T_{t}$ is total simulation time and the unit is "s," and $q_{t}$ is the total passengers in all simulation regions.

(2) Effect of Conflicting Points $u_{22}$. This index represents the proportion of passengers who go through the conflicting points:

$$
u_{22}=\frac{\sum_{i=1}^{n} q_{i}}{q_{t}} .
$$

In the type, $q_{i}$ stands for the number of affected passengers in conflicting point $i, q_{t}$ stands for the total passengers during the simulation time, and $n$ is the number of conflicting points.

3.1.3. Effectiveness Index. Effectiveness refers to the execution efficiency in pedestrians' evacuation process.

(1) Average Evacuation Time $u_{31}$. For passengers, evacuation time can reflect evacuation efficiency intuitively:

$$
u_{31}=\frac{\sum_{i=1}^{q_{t}} t_{i}}{q_{t}} .
$$

In the type, $t_{i}$ stands for the evacuation time of passenger $i$ and the unit is " $\mathrm{s}$ " and $q_{t}$ stands for the total passengers during the simulation time.

(2) The Number of Evacuation Passengers in Unit Time $u_{32}$. According to "Design Specifications for Subway," the longest evacuation time is not more than 6 minutes in subway station. The number of evacuation passengers in unit time can also reflect evacuation efficiency. The formula is as follows:

$$
u_{32}= \begin{cases}\frac{Q}{T} & T \leq 6 \\ \frac{Q}{6} & T>6\end{cases}
$$

In the type, $Q$ stands for the number of evacuation passengers in 6 minutes; $T$ stands for the whole evacuation time.

3.1.4. Orderliness Index. Orderliness mainly reflects the order of pedestrians' evacuation process. Good order can ensure safety and comfort.

(1) Round Coefficient $u_{41}$. This index reflects the convenience of pedestrians' evacuation in integrated transport hub:

$$
u_{41}=\sum_{i=1}^{r} \sum_{j=1}^{s} w_{i j} \frac{\sum_{k=1}^{O_{i j}} l_{i j k}}{O_{i j} \cdot S_{i j}} .
$$

In the type, $r$ is the total number of starting points, $s$ is the total number of terminal points, $O_{i j}$ is the number of passengers from starting point $i$ to terminal point $j, S_{i j}$ stands for the shortest distance from $i$ to $j$ and the unit is " $\mathrm{m}$," and $l_{i j k}$ stands for the actual working distance of passenger $k$ from origin $i$ to destination $j . w_{i j}$ is weight of $i$ to $j$. Considering the passenger flow of each OD pair, $w_{i j}$ can be calculated based on entropy weight coefficient method. Based on information theory [13], the entropy of OD pair $i j$ is

$$
\begin{gathered}
H_{i j}=-\frac{1}{\ln n} \sum_{l=1}^{n} h_{i j l} \ln h_{i j l}, \\
h_{i j l}=\frac{o_{i j l}}{\sum_{l=1}^{n} o_{i j l}},
\end{gathered}
$$

where $n$ is the number of fire evacuation plans.

The weight of OD pair $i j$ is

$$
w_{i j}=\frac{\left(1-H_{i j}\right)}{\left(r \times s-\sum_{i=1}^{r} \sum_{j=1}^{s} H_{i j}\right)} .
$$

(2) The Diversity of Speed $u_{42}$. The index reflects orderliness of evacuation process directly. The formula is as follows:

$$
u_{42}=\sqrt{\frac{\sum_{i=1}^{n}\left(v_{i}-\bar{v}\right)^{2}}{n}} .
$$

In the type, $v_{i}$ is evacuation speed of period $i, n$ is the number of simulation time periods, and $\bar{v}$ is the average speed during the whole simulation.

3.2. Matter-Element Evaluation Algorithm. Many algorithms can be used to sort the best plan such as cosine function, linear assignment, fuzzy logic, and matter-element algorithm [14-16]. This paper uses matter-element analysis to calculate the value of decision-making of each plan. The main theories of this algorithm are the definition of matter-element, extension mathematics, and the matter-element transformation theory [17-20]. It has been widely used in evaluation fields. In this paper, a specific matter-element algorithm is established based on the dynamic evaluation indicators system.

3.2.1. Normalization of Decision-Making Matrix. It is assumed that there are $n$ fire evacuation plans in subway station noted to $S=\left\{S_{1}, S_{2}, \ldots, S_{n}\right\}$. The index set of second grade is $P=\left\{P_{1}, P_{2}, \ldots, P_{n}\right\}$. Then the decision-making matrix of plan $S_{i}$ with matter-element algorithm can be written as follows:

$$
Y_{i}=\left[\begin{array}{ccc}
A_{i} & P_{1} & y_{i 1} \\
& P_{2} & y_{i 2} \\
& \vdots & \vdots \\
& P_{m} & y_{i m}
\end{array}\right] \begin{gathered}
\omega_{1} \\
\omega_{2} \\
\vdots \\
\omega_{m}
\end{gathered} \quad i=1,2, \ldots, n .
$$

Each index has different units and needed to be normalized. To define index set $P^{+}=$indexes of bigger better $\}$and 
to define $P^{-}=$indexes of smaller better $\}$, then normalization process can be represented as follows:

$$
\begin{aligned}
& r_{i j}=\frac{\left(y_{i j}-\min _{1 \leq i \leq n} y_{i j}\right)}{\left(\max _{1 \leq i \leq n} y_{i j}-\min _{1 \leq i \leq n} y_{i j}\right)}, \quad i=1,2, \ldots, n, j \in P^{+}, \\
& r_{i j}=\frac{\left(\max _{1 \leq i \leq n} y_{i j}-y_{i j}\right)}{\left(\max _{1 \leq i \leq n} y_{i j}-\min _{1 \leq i \leq n} y_{i j}\right)}, \quad i=1,2, \ldots, n, j \in P^{-} .
\end{aligned}
$$

The normalized matter-element algorithm matrix of plan $S_{i}$ can be represented as follows:

$$
R_{i}=\left[\begin{array}{ccc}
A_{i} & P_{1} & r_{i 1} \\
& P_{2} & r_{i 2} \\
& \vdots & \vdots \\
& P_{m} & r_{i m}
\end{array}\right] \begin{gathered}
\omega_{1} \\
\omega_{2} \\
\vdots \\
\omega_{m}
\end{gathered} \quad i=1,2, \ldots, n .
$$

3.2.2. The Best and Worst Matrix. To define

$$
\begin{gathered}
r_{j}^{+}= \begin{cases}\max _{1 \leq i \leq n} r_{i j}, & j \in P^{+} \\
\min _{1 \leq i \leq n} r_{i j}, & j \in P^{-},\end{cases} \\
r_{j}^{-}= \begin{cases}\min _{1 \leq i \leq n} r_{i j}, & j \in P^{-} \\
\max _{1 \leq i \leq n} r_{i j}, & j \in P^{+},\end{cases}
\end{gathered}
$$

then the best and worst matrix can be represented as follows:

$$
\begin{gathered}
R^{+}=\left[\begin{array}{ccc}
A_{i} & P_{1} & r_{1}^{+} \\
& P_{2} & r_{2}^{+} \\
& \vdots & \vdots \\
& P_{m} & r_{m}^{+}
\end{array}\right] \begin{array}{c}
\omega_{1} \\
\omega_{2} \\
\vdots \\
\omega_{m}
\end{array} \\
R^{-}=\left[\begin{array}{ccc}
A_{i} & P_{1} & r_{1}^{-} \\
& P_{2} & r_{2}^{-} \\
& \vdots & \vdots \\
& P_{m} & r_{m}^{-}
\end{array}\right] \begin{array}{c}
\omega_{1} \\
\omega_{2} \\
\vdots \\
\omega_{m}
\end{array}
\end{gathered}
$$

3.2.3. Weights Calculation. In this paper, APN method is used to calculate the weight of each index $[21,22]$.

3.2.4. The Distance and Relative Closeness. To define $S_{i}^{+}$as the distance from plan $S_{i}(i=1,2, \ldots, n)$ to the best plan and $S_{i}^{-}$ as the distance to the worst plan

$$
\begin{aligned}
& S_{i}^{+}=\sqrt{\sum_{j=1}^{m} \omega_{j}^{2}\left(r_{i j}-R^{+}\right)^{2}}, \\
& S_{i}^{-}=\sqrt{\sum_{j=1}^{m} \omega_{j}^{2}\left(r_{i j}-R^{-}\right)^{2}},
\end{aligned}
$$

TABLE 3: The number of passengers for evacuation.

\begin{tabular}{ccc}
\hline Places & Arriving person & Waiting person \\
\hline Line 10 up & 1200 & 300 \\
Line 10 down & 1200 & 300 \\
Line 5 & 700 & 300 \\
Line Yizhuang & 700 & 300 \\
\hline Subway hall & - & 450 \\
\hline
\end{tabular}

then the relative closeness of plan $S_{i}(i=1,2, \ldots, n)$ to the best plan is $e_{i}$ :

$$
e_{i}=\frac{S_{i}^{-}}{S_{i}^{+}+S_{i}^{-}} \text {. }
$$

In the type, $e_{i}$ is the value of decision-making of plan $S_{i}$ and $0<e_{i}<1$. When $e_{i}$ is bigger, $S_{i}^{+}$is closer to 0 and the evacuation plan is better.

\section{Test Results}

4.1. Simulation Model. In order to test the practicability of evacuation evaluation system in subway fire, the paper chooses Songjiazhuang (SJZ) station as an example. SJZ is a transfer station of line 10, line 5, and line Yizhuang. It is predicted that the peak hour traffic of SJZ will reach 66800 in 2016. There is no doubt that it will be one of the most large-scale subway stations in Asia. Therefore it is particularly important to evaluate the fire evacuation plans of SJZ.

4.1.1. Data Preparation. Data preparation is the basic work for pedestrian simulation modeling. The number of passengers in subway platform and subway hall is shown in Table 3 through field investigation.

4.1.2. Fire Environment. In order to reflect the evacuation conditions of different fire scenes in subway, in this paper, two different scenarios are simulated. Exhaust mode settings are shown in Table 4 and the distribution of fire product in platform is shown in Figure 3.

4.1.3. Speed Calibration of Fire Environment. Equivalent velocity is the movement speed in fire environment. The paper considered the impact of mainly fire products on personnel evacuation separately:

$$
v=v_{0} \cdot f\left(K_{s}, \rho, T\right)=v_{0} \cdot f_{1}\left(K_{s}\right) f_{1}(\rho) f_{1}(T),
$$

where $v$ is equivalent velocity, $v_{0}$ is pedestrian normal velocity, $f_{1}\left(K_{s}\right)$ is visibility influence coefficient, $f_{1}(\rho)$ is toxic gas concentration influence coefficient, and $f_{1}(T)$ is temperature influence coefficient.

(1) The Effect of Visibility on Pedestrian Speed. The relationship between people' walking speed and smoke obscuration coefficient when people were exposed to the irritating and nonirritating smoke is shown in Figure 4 by experiment [23]. 

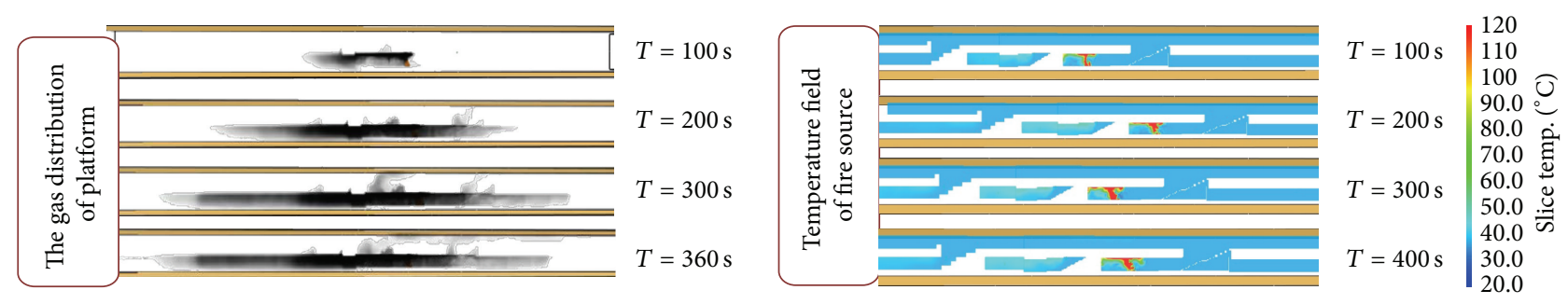

Mesh: 1
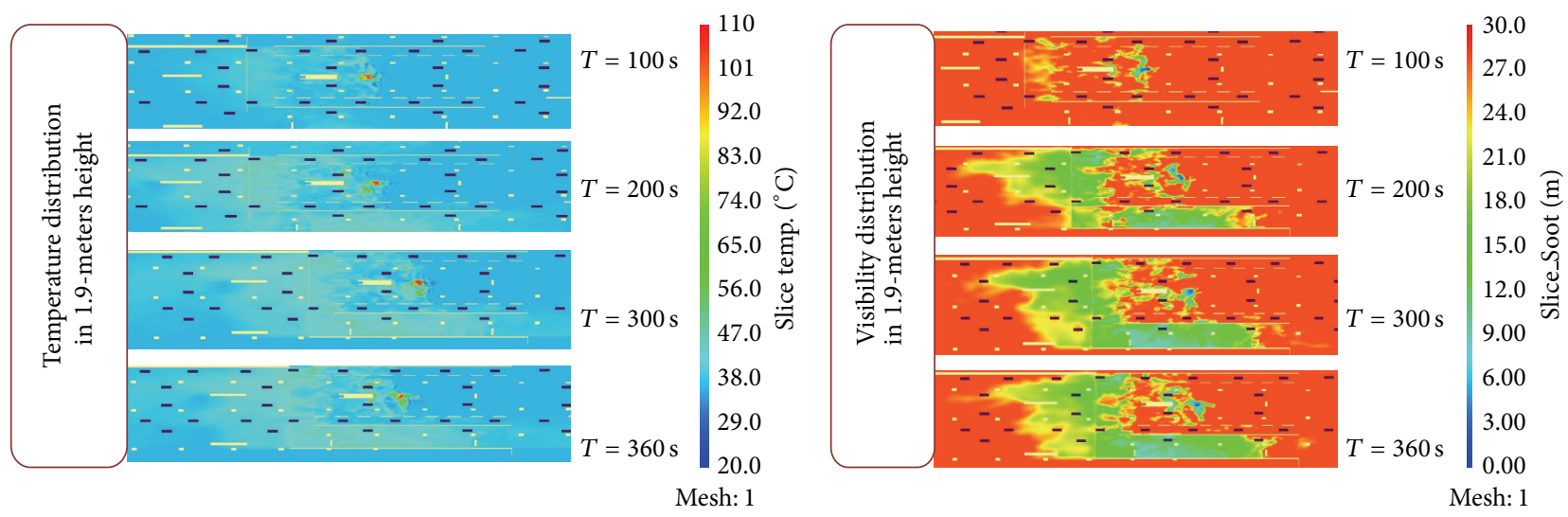

FIGURE 3: Fire product distributed in platform.

TABLE 4: Exhaust mode settings in different fire scenes.

\begin{tabular}{lccc}
\hline Fire scenes & Exhaust smoke level & Exhaust smoke model & Remark \\
\hline Fire of platform & 180 & Exhaust smoke of platform & All of the shield doors open for auxiliary exhausting smoke \\
Fire of hall & 180 & Exhaust smoke of hall & All of the shield doors open for auxiliary exhausting smoke \\
\hline
\end{tabular}

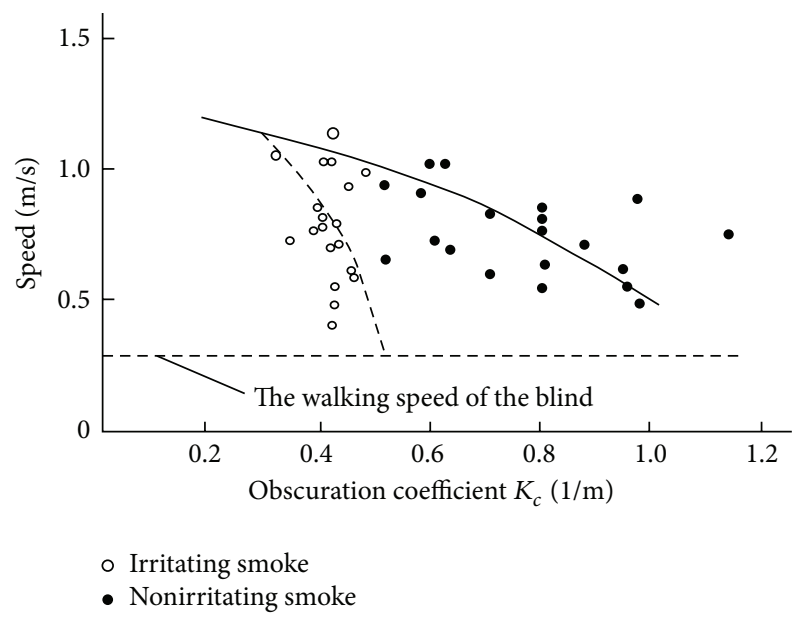

FIGURE 4: The walking speed in irritating and nonirritating smoke.

(2) The Effect of Toxic Gas on Pedestrian Speed. The effect of toxic gas on evacuation pedestrian is velocity-decrease. Milke had got the data by experiment about the effect of different concentrations of CO on pedestrian in fire [24] shown in Table 5.
(3) The Effect of Temperature on Pedestrian Speed. According to the predecessors' research data, the influence coefficient of flue gas temperature on personnel movement speed can be concluded as follows:

$$
f_{3}(T)=\left\{\begin{array}{l}
1 \quad\left(T_{0}<T_{s} \leq T_{\sigma 1}\right) \\
\frac{\left(v_{\max }-1.2\right)\left(\left(T_{s}-T_{\sigma 1}\right) /\left(T_{\sigma 2}-T_{\sigma 1}\right)\right)^{2}}{v_{0}}+1 \\
\quad\left(T_{\sigma 1}<T_{s} \leq T_{\sigma 2}\right) \\
\frac{v_{\max }}{1.2}\left[1-\left(\frac{T_{s}-T_{\sigma 2}}{T_{\text {deal }}-T_{\sigma 2}}\right)^{2}\right] \\
\left(T_{\sigma 2}<T_{s} \leq T_{\text {deal }}\right),
\end{array}\right.
$$

where $T_{s}$ is the temperature in the fire, $v_{0}$ is pedestrians normal velocity, $v_{\max }$ is maximum speed to escape, generally taking $5 \mathrm{~m} / \mathrm{s}, T_{\sigma 1}$ is the temperature when people feel uncomfortable, generally taking $30^{\circ} \mathrm{C}, T_{\sigma 2}$ is the temperature that harm a person, generally taking $60^{\circ} \mathrm{C}$, and $T_{\sigma 2}$ is the temperature that cause death, generally taking $120^{\circ} \mathrm{C}$.

4.1.4. Pedestrian Survival Condition Calibration. All kinds of fire products occurring in the process of fire have 
TABLE 5: Different concentrations of CO impact on pedestrian in fire.

\begin{tabular}{lccc}
\hline Co (\%) & $\begin{array}{c}\text { Exposure } \\
\text { time (min) }\end{array}$ & $\begin{array}{c}\text { Cumulative } \\
\text { dose (\%min) }\end{array}$ & $\begin{array}{c}\text { Personnel } \\
\text { velocity } \\
\text { decrease }(\mathrm{m} / \mathrm{s})\end{array}$ \\
\hline \multirow{3}{*}{$>0.1$} & 1 & $>0.1$ & 0.05 \\
& 2 & $>0.2$ & 0.1 \\
$>0.15$ & $n$ & $>0.1 n$ & $0.05 n$ \\
\hline & 2 & $>0.15$ & 0.1 \\
$>0.2$ & $n$ & $>0.3$ & 0.2 \\
& 1 & $>0.15 n$ & $0.1 n$ \\
\hline$>0.25$ & 2 & $>0.4$ & 0.15 \\
\hline
\end{tabular}

TABLE 6: Human tolerance limits to fire products.

\begin{tabular}{ll}
\hline Content & Human tolerance limits \\
\hline $\begin{array}{l}\text { Radiation heat } \\
\text { flux }\end{array}$ & $2.5 \mathrm{kw} / \mathrm{m}^{2}$ \\
\hline Gas temperature & $\begin{array}{l}\text { When the smoke layer height }>2 \mathrm{~m}, 180^{\circ} \mathrm{C} \\
\text { When }<2 \mathrm{~m} \text { for } 30 \mathrm{~min}, 60^{\circ} \mathrm{C}\end{array}$ \\
\hline Visibility & $\begin{array}{l}\text { When the smoke layer height }<2 \mathrm{~m}, 0.1 \mathrm{~m} \\
(10 \mathrm{~cm})\end{array}$ \\
\hline Toxic gas & $\mathrm{CO}$ concentration achieves $0.25 \%$ \\
\hline
\end{tabular}

a great threat to pedestrians' life. The third edition of Fire handbook in China gives human tolerance limits to different fire products (Table 6).

\subsubsection{Evacuation Routes Calibration}

Plan 1. According to the layout of metro station and passenger flow forecast, the mode of passenger evacuation from the nearest exit is shown in Figure 5.

Plan 2. Because of the uneven distribution of passengers in the platform, it is suggested that part of passengers is guided to other exits which are not nearest to them. The specific measures are shown in Figure 6, guiding 300 passengers in line 10 platform to exits in line 5 and line Yizhuang platform.

4.2. Results of Evaluation. Based on the output data of simulation model, the value of the evaluation indexes of two evacuation plans in two scenes can be calculated, as shown in Table 7.

The value of decision-making of different plans can be calculated by the matter-element algorithms, as shown in Table 8.

From the results, when the platform is on fire, $e_{2}>e_{1}$. It shows that $\mathbf{S}_{2}$ is better than $\mathbf{S}_{1}$. When the hall is on fire, $e_{2}>e_{1}$. It also shows that $\boldsymbol{S}_{2}$ is better than $\mathbf{S}_{1}$. According to the value of decision-making in two scenes, it is known

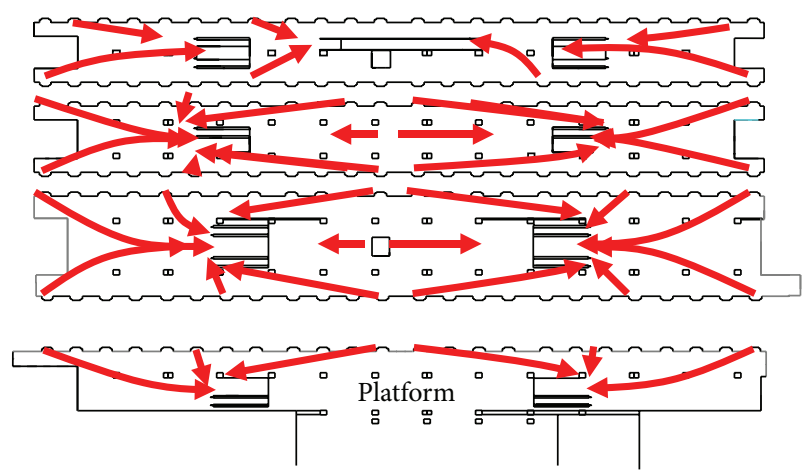

FIgURE 5: The evacuation route of plan 1.

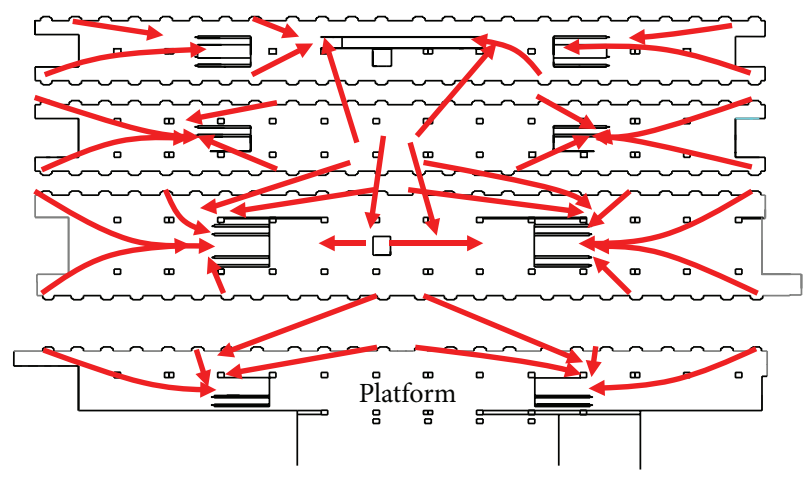

FIgURE 6: The evacuation route of plan 2.

TABLE 7: The value of evaluation indexes of two plans in two scenes.

\begin{tabular}{|c|c|c|c|c|}
\hline \multirow{2}{*}{$\begin{array}{l}\text { Evaluation } \\
\text { indexes }\end{array}$} & \multicolumn{2}{|c|}{ Subway platform on fire } & \multicolumn{2}{|c|}{ Subway hall on fire } \\
\hline & $\operatorname{Plan} 1\left(\mathbf{S}_{\mathbf{1}}\right)$ & Plan $2\left(\mathbf{S}_{2}\right)$ & $\operatorname{Plan} 1\left(\mathbf{S}_{\mathbf{1}}\right)$ & Plan $2\left(\mathbf{S}_{\mathbf{2}}\right)$ \\
\hline$u_{11}$ & 99.35 & 99.57 & 99.82 & 99.88 \\
\hline$u_{12}$ & 0.943 & 0.942 & 0.969 & 0.966 \\
\hline$u_{21}$ & 0.763 & 0.783 & 0.782 & 0.773 \\
\hline$u_{22}$ & 0.639 & 0.623 & 0.659 & 0.624 \\
\hline$u_{31}$ & 278 & 221 & 271 & 216 \\
\hline$u_{32}$ & 678 & 741 & 691 & 761 \\
\hline$u_{41}$ & 1.36 & 1.32 & 1.33 & 1.21 \\
\hline$u_{42}$ & 0.18 & 0.14 & 0.16 & 0.13 \\
\hline
\end{tabular}

that the fire evacuation effect in hall is better than in platform regardless of plans.

4.3. Analysis of Simulation Results. From the value of evaluation indexes of two plans shown in Table 7, we know the following.

(1) More people can escape in plan 2 and the others will die in line 10 platform from the simulation process. Figure 7 shows the relationship between the number of people present in the subway and the evaluation time of two plans. It is obvious that the escape speed of plan 2 is faster than plan 1.

(2) The comparison of security risk shows the effect of high density passenger and the number of conflicts 


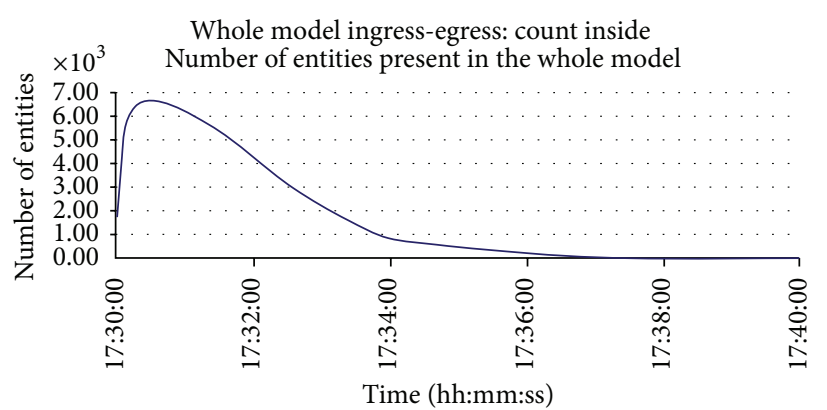

(a) Plan 1



(b) Plan 2

FIGURE 7: The relationship between the number of people present in the subway and the evaluation time.

TABLE 8: The value of decision-making of different scenes.

The value of Subway platform on fire Subway hall on fire decision-making Plan $1\left(\mathbf{S}_{1}\right) \quad$ Plan $2\left(\mathbf{S}_{2}\right) \quad$ Plan $1\left(\mathbf{S}_{1}\right)$ Plan $2\left(\mathbf{S}_{2}\right)$

\begin{tabular}{lllll}
\hline$e_{i}$ & 0.198 & 0.366 & 0.730 & 0.896 \\
\hline
\end{tabular}

is less in plan 2. It is proved that the evacuation organization of plan 2 is more reasonable.

(3) The comparison of effectiveness index shows the average evacuation time of plan 2 is less, although part of people did not evacuate from the nearest exits.

(4) The comparison of orderliness index shows the diversity of speed is smaller, so the evacuation flow is more uniform and orderly in plan 2.

\subsection{Simulation Conclusion and Optimization}

(1) Because of the uneven distribution of passengers in subway, the plan that all pedestrians evacuate from the nearest exits is not the best. Guiding a certain number of passengers to other exits may be more suitable.

(2) The evacuation time of pedestrians in line 10 platform is the longest from the simulation process; it is suggested that the new emergency stair or channel of line 10 platform should be added.

\section{Conclusion}

With the continuous improvement of urban subway system in China, the ability of subway stations to prevent the disasters and accidents will face a huge challenge. In the practical application, a model of pedestrians' evacuation process in subway fire and a dynamic evaluation indicators system are shown in this paper. The test results prove them to be applied and effective. The evaluation indicators system provides a new method to evaluate the facility layout and evacuation plan quantitatively. It also has a strong guiding significance for optimizing evacuation plan and improving the ability to prevent the disasters and accidents of subway stations.

\section{Conflict of Interests}

The authors declare that there is no conflict of interests regarding the publication of this paper.

\section{Acknowledgment}

This paper was sponsored by the Natural Science Foundation of Beijing (Project no. Z1004011201301).

\section{References}

[1] Y. Peizhong, W. Xin, and L. Tao, "Agent-based simulation of fire emergency evacuation with fire and human interaction model," Safety Science, vol. 49, no. 8-9, pp. 1130-1141, 2011.

[2] S. Sharma, "AvatarSim: a multi-agent system for emergency evacuation simulation," Journal of Computational Methods in Sciences and Engineering, vol. 9, no. 1, pp. 13-22, 2009.

[3] X. Guo, J. Chen, Y. Zheng, and J. Wei, "A heterogeneous lattice gas model for simulating pedestrian evacuation," Physica A: Statistical Mechanics and its Applications, vol.391, no. 3, pp. 582592, 2012.

[4] H. Gotoh, E. Harada, and E. Andoh, "Simulation of pedestrian contra-flow by multi-agent DEM model with self-evasive action model," Safety Science, vol. 50, no. 2, pp. 326-332, 2012.

[5] P. A. Thompson and E. W. Marchant, "A computer model for the evacuation of large building populations," Fire Safety Journal, vol. 24, no. 2, pp. 131-148, 1995.

[6] J. S. Roh, H. S. Ryou, W. H. Park, and Y. J. Jang, "CFD simulation and assessment of life safety in a subway train fire," Tunnelling and Underground Space Technology, vol. 24, no. 4, pp. 447-453, 2009.

[7] A. Haack and J. Schreyer, "Emergency scenarios for tunnels and underground stations in public Transport," Tunnelling and Underground Space Technology, vol. 21, no. 3-4, pp. 285-294, 2006.

[8] M. Zhong, C. Shi, X. Tu, T. Fu, and L. He, "Study of the human evacuation simulation of metro fire safety analysis in China," Journal of Loss Prevention in the Process Industries, vol. 21, no. 3, pp. 287-298, 2008.

[9] J. J. Berrou, J. Beecham, and P. Quaglia, "Calibration and validation of the Legion simulation model using empirical data," in Pedestrian and Evacuation Dynamics 2005, pp. 167-181, Springer, Berlin, Germany, 2007. 
[10] K. McGrattan and S. Hostikka, Fire Dynamics Simulator (Version5) Technical Reference Guide, National Institute of Standards and Technology, Gaithersburg, Md, USA, 2007.

[11] J. Lord, B. Meaeham, A. Moore, and R. Fahy, "Guide for evaluating the predictive capabilities of computer egress models," National Institute of Standards and Technology GCR 06-886, 2005.

[12] J. J. Fruin, Pedestrian Planning and Design, Metropolitan Association of Urban Designers and Environmental Planners, New York, NY, USA, 1971.

[13] Q. L. Yang and Y. B. Guo, "Application of the fuzzy matter-element model based on coefficients of entropy to evaluation of urban eco-security," Mathematics in Practice and Theory, vol. 40, no. 19, pp. 62-67, 2010.

[14] V. López, M. Santos, and J. Montero, "Fuzzy specification in real estate market decision making," International Journal of Computational Intelligence Systems, vol. 3, no. 1, pp. 8-20, 2010.

[15] M. Ekmekçioğlu, A. C. Kutlu, and C. Kahraman, "A fuzzy multi-criteria SWOT analysis: an application to nuclear power plant site selection," International Journal of Computational Intelligence Systems, vol. 4, no. 4, pp. 583-595, 2011.

[16] J.-F. Ding and C.-C. Chou, "A fuzzy MCDM model of service performance for container ports," Scientific Research and Essays, vol. 6, no. 3, pp. 559-566, 2011.

[17] G. Zhang, Y. Chen, P. Li, and S. Fibbe, "Study on evaluation indicators system of crowd management for transfer stations based on pedestrian simulation," International Journal of Computational Intelligence Systems, vol. 4, no. 6, pp. 1375-1382, 2011.

[18] Q. Li, X. H. She, and K. C. P. Wang, "An exploration of matterelement analysis for pavement preventive maintenance optimal timing determination and treatment selection," in Proceedings of the 89th Annual Meeting of the Transportation Research Board, Washington, DC, USA, 2010.

[19] D. Liu and Z. Zou, "Water quality evaluation based on improved fuzzy matter-element method," Journal of Environmental Sciences, vol. 24, no. 7, pp. 1210-1216, 2012.

[20] J. Zhang, K. Wang, X. Chen, and W. Zhu, "Combining a fuzzy matter-element model with a geographic information system in eco-environmental sensitivity and distribution of land use planning," International Journal of Environmental Research and Public Health, vol. 8, no. 4, pp. 1206-1221, 2011.

[21] M. Dağdeviren and I. Yüksel, "A fuzzy analytic network process (ANP) model for measurement of the sectoral competititon level (SCL)," Expert Systems with Applications, vol. 37, no. 2, pp. 1005-1014, 2010.

[22] T. L. Saaty, "Time dependent decision-making; dynamic priorities in the AHP/ANP: generalizing from points to functions and from real to complex variables," Mathematical and Computer Modelling, vol. 46, no. 7-8, pp. 860-891, 2007.

[23] T. Jim and T. Yamada, "Irritating effects of fire smoke on visibility," Fire Science and Technology, vol. 5, no. 1, pp. 79-90, 1985.

[24] J. A. Milke, "Evaluating the early development of smokehazard from fires in large spaces," ASHRAE Transactions, vol. 106, no. 2, pp. 627-636, 2000. 




Advances in

Operations Research

mansans

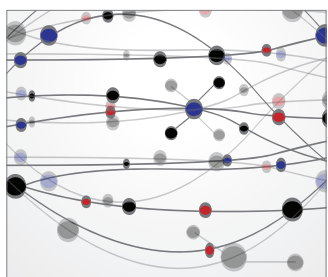

The Scientific World Journal
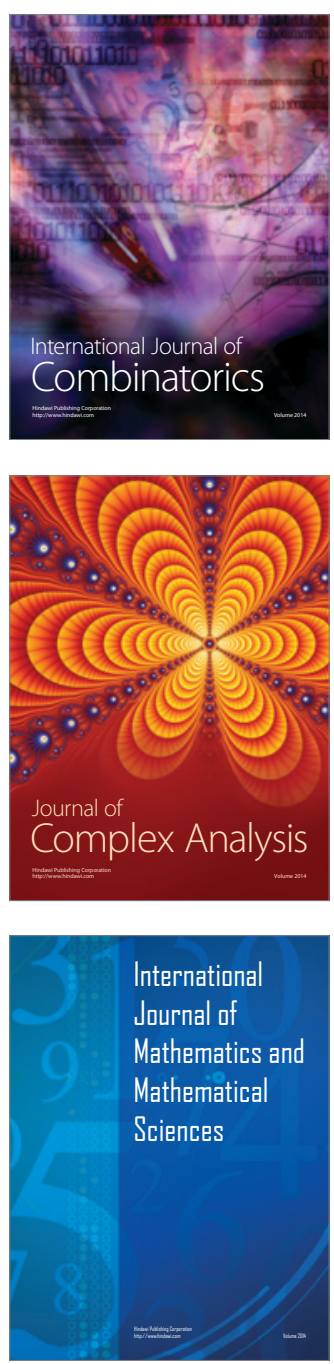
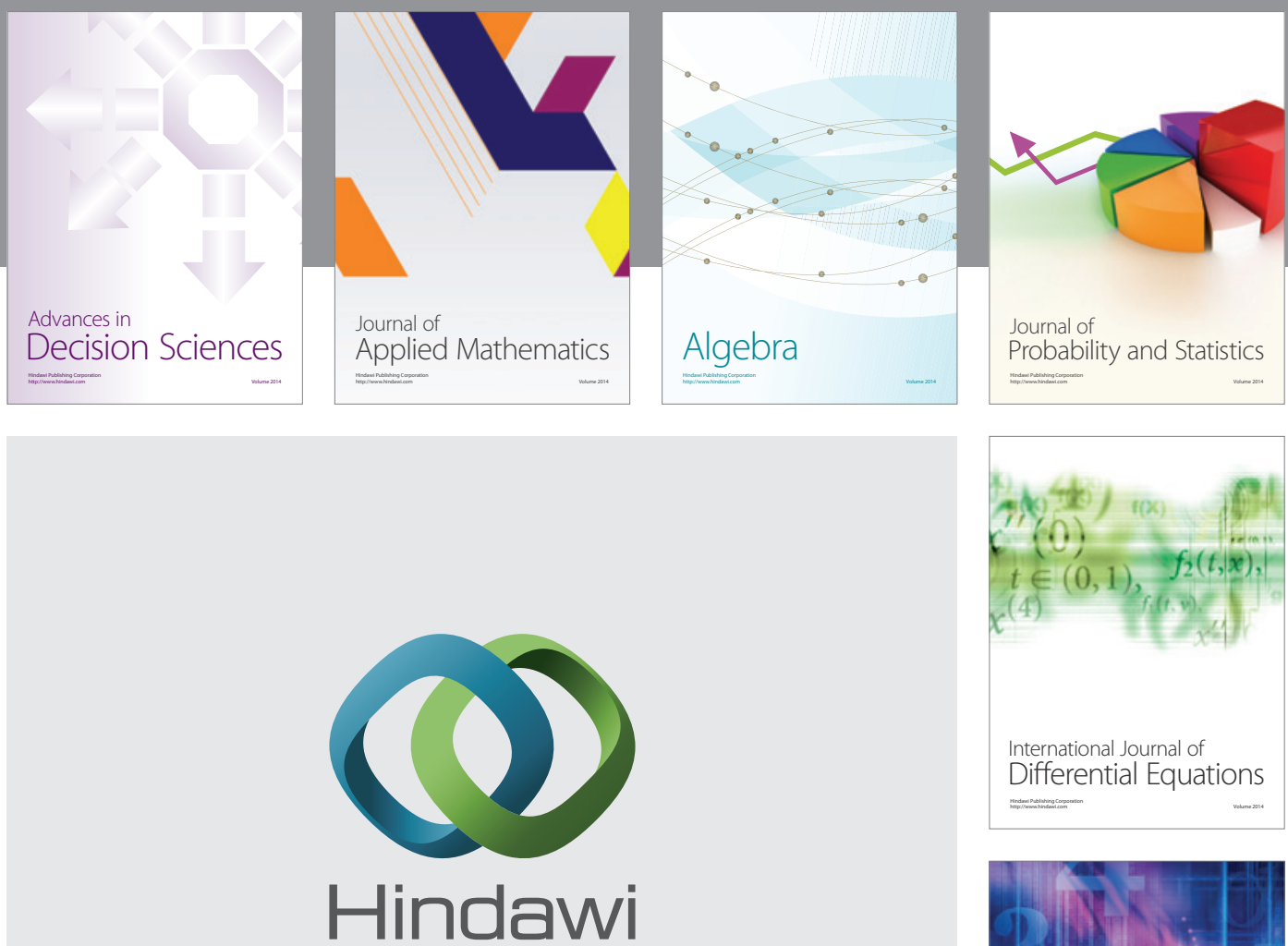

Submit your manuscripts at http://www.hindawi.com


Journal of

Function Spaces

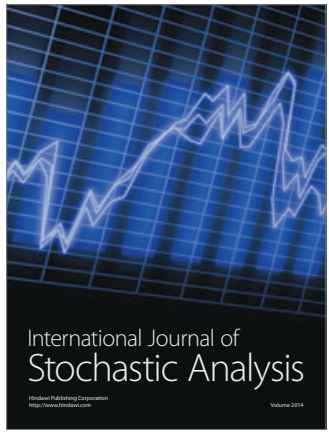

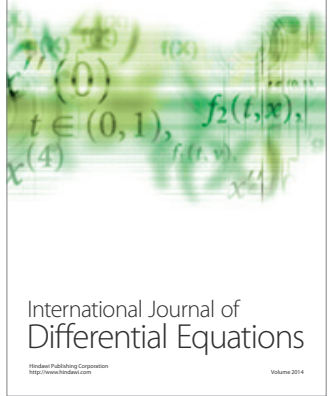
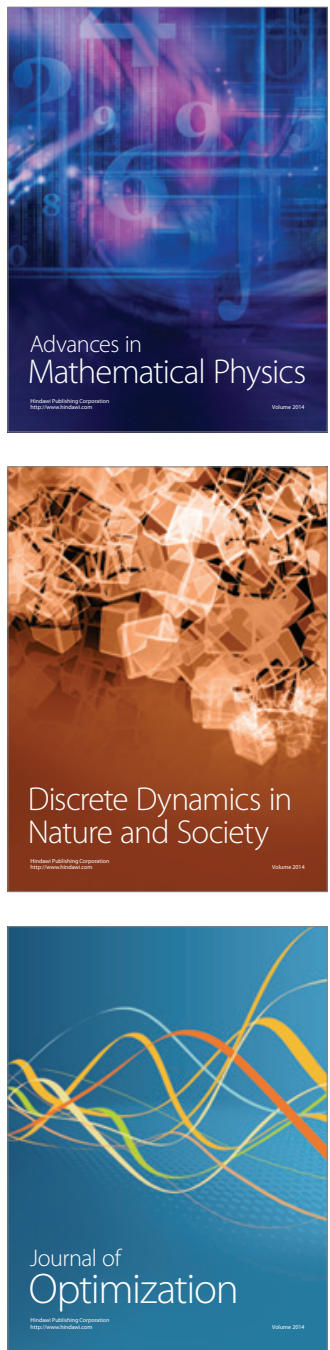